\title{
LA MAUROFILIA COMO IDEAL CABALLERESCO EN LA LITERATURA CRONISTTICA DEL XIV Y XV
}

\author{
Amelia Garcia-Valdecasas \\ (UNED y Universidad de Valencia) \\ Rafael Beltrán Llavador \\ (Universidad de Valencia)
}

La sociedad medieval ha sido descrita con frecuencia como una sociedad fundamentalmente militar. Sería seguramente muy poco exacto, sin embargo, imaginar una Edad Media en constante estado de beligerancia, incesantemente entregada a la violencia de la guerra ${ }^{1}$. Al final de la Edad Media, la guerra era fundamentalmente de desgaste, de saqueo y ocupación, de defensa y disuasión. Así fue también, en gran parte, la guerra de la reconquista, un fenómeno que marcó la evolución de los reinos hispánicos durante los últimos siglos de nuestro Medievo. Una reconquista que conoció aceleraciones y detenciones, victorias y derrotas, alguno de cuyos héroes más afamados, como el mismo Rodrigo Díaz de Vivar, sirvieron y combatieron alternativamente a príncipes cristianos y musulmanes, aparentemente sin especiales traumas ni complejos de traición. La supervivencia de importantes núcleos musulmanes dentro de los estados cristianos y la coexistencia en el mismo solar peninsular del reino de Granada sería un fenómeno histórico pródigo en consecuencias sociales y también estéticas, en concreto literarias ${ }^{2}$.

La historiografia musulmana tiene un papel esencial dentro de las letras peninsulares hasta la época de Pero López de Ayala, pero a partir de la

' Philippe Contamine, La guerra en la Edad Media, Labor, Barcelona, 1984, pp. 386-7. Véase también B. Guenée, Occidente durante los siglos XIV y XV, Barcelona, Labor, 1973, p. 14: "en el fondo, la batalla sólo fue un accidente bastante raro en la guerra del final de la Edad Media". Afirmaciones justamente matizadas por Maurice Keen, La caballería, Madrid, Ariel, 1986, esp. cap. XII, pp. 289-99.

2 Véase, sólo para una iniciación al tema, S. Sobrequés, «La Baja Edad Media peninsular» en J. Vicens Vives, Historia de España y América social y económica, Barcelona, Vicens-Vives, 1979. pp. $339-348$. 
obra histórica del Canciller esa producción pasa a ser prácticamente inexistente en nuestra península ${ }^{3}$. Sin embargo, la misma historiografia cristiana, en cierta medida influenciada por algunas obras árabes, tomará el relevo en el reflejo de actitudes de los vecinos y enemigos. Si la función principal del historiador medieval es la "narratio rei gestae», que ya dictaba Isidoro de Sevilla, función inseparable de la exigencia de la verdad, basada en el derecho tradicional, el hecho mismo, independientemente de los tintes del dibujo, de reflejar al enemigo en la cronistica del XIV y XV, significa que se les concedía un valor muy importante, lejano del desprecio simplificador al que la propaganda imperial más burda nos acostumbró durante algún tiempo".

Hoy en día empezamos a conocer mejor el valor que se debe conceder a la narración histórica y las limitaciones que, como relato, como forma lingüística, está obligada a tener. Para la historia medieval se ha hablado despectivamente, con total falta de perspectiva, de verdad deformada, de discurso meramente descriptivo y no crítico ni analítico, de aplicación de esquemas, etiquetas y arquetipos... Pero resulta que todo eso es la historia, es decir una de las muchas posibles historias 5 .

La consideración del moro con simpatía y su idealización, muestra de una incipiente maurofilia, era algo común en la literatura medieval, no exclusivo de la literatura cronística, ya que a medida que el prestigio de los reyes granadinos se iba reduciendo históricamente, el moro fue ganando popularidad en la literatura, desde el romancero a la lírica popular y cortés, como personaje representativo. Los escritos de don Juan Manuel muestran ya la concepción caballeresca del moro y la exaltación de sus ciudades como

${ }^{3}$ B. Sánchez Alonso, Historia de la historiografia española (hasta la publicación de la Crónica de Ocampo) (...-1543), 2." ed. Madrid, CSIC, 1947, p. 353.

4 Véase para el trabajo del historiador medieval, B. Guénée, Histoire et culture historique dans l'occident médieval, Aubier, Paris, 1980, esp. caps. III-V, y para el problema de la veracidad histórica, pp. 332-353. El mismo Canciller López de Ayala advertirá, al inicio de sus crónicas, que va a hablar "... de lo que ví, en lo qual non entiendo dezir sinon verdads (Pero López de Ayala, Proemio a las Crónicas de los Reyes de Castilla, ed. BAE, p. 400). La misma condición exige Pérez de Guzmán en sus Generaciones y semblanzas: "que él [el historiador] sea presente a los prinçipales e notables abtos de guerra e de paz» (ed. Dominguez Bordona, Madrid, La Loctura, 1924, p. 5).

${ }^{5}$ Véase Paul Veyne, Cómo se escribe la historia. Foucault revoluciona la historia, Madrid, Alianza Editorial, 1984: klos historiadores cuentan historias, que son como los itinerarios que han decidido seguir a través del campo objetivo de acontecimientos (...) ningun historiador describe la totalidad de ese campo, pues al tener que escoger un itinerario no puede recorrerlo en toda su amplitud; ninguno de esos itinerarios es el verdadero, ninguno es la Historia" (p.37); cfr. Manuel Cruz Rodríguez, Narratividad: la nueva sintesis, Barcelona, Peninsula, 1986: "La historia es un modo de contarnos lo que ha sucedido de acuerdo con determinadas reglas y a partir de otros relatos ya existentes (...) Siempre que se trate de contar algo, la materia prima es una historia (a ser pasible una buena historia). No un material empírico bruto, sino un determinado recorte de la realidad, un particular enfoque o encuadre de la misman (p. 17). 
centros de refinamiento y riqueza, debido a que este autor era un hombre de frontera, y también al retroceso que en esta época sufre la reconquista, en parte por las alianzas que algunos caballeros, como el propio don Juan Manuel, establecieron con el rey de Granada en detrimento del de Castilla, lo que favoreció el intercambio cultural entre el mundo árabe y el cristiano.

\section{LA REPRESENTACIÓN CRONISTICA}

Para tratar de mostrar algunos reflejos maurofilicos, o de estilización morisca, a lo largo de la historiografia castellana de los siglos XIV y XV, hemos seleccionado cinco crónicas, con la pretensión de que resulten representativas del ancho abanico que abarcan los principales reinados de estos siglos. Desde diferentes posturas literarias, de la autoría al anonimato, de la cronística real a la crónica biográfica, de la crónica oficial y profesional hasta el trabajo personal, estas obras parten del denominador común de presentar unas actitudes muy semejantes de respeto, $e$ incluso aprecio, hacia el enemigo secular.

La Gran crónica de Alfonso XI constituye, en palabras de Diego Catalán, su descubridor, una "hábil reelaboración de la historia de Alfonso XI, hecha en vista de una novedosa concepción del arte de historiar" ${ }^{7}$. Siguiendo el símil cinematográfico que el mismo Catalán utilizara en su primer estudio sobre la obra ${ }^{8}$, este enorme monumento literario permanece como la mejor película de la historia castellana del xv y, pese a hallarse incompleta, la mayor fuente cronística que poseemos sobre el reinado del último Alfonso de la historia medieval de Castilla.

Como ha resumido perfectamente Michel Garcia, nadie más representativo, entre el grupo dominante de la sociedad castellana desde el reinado de Juan I al de Enrique III, que el Canciller Pero López de Ayala, y nada más útil que una crónica oficial, para expresar y propagar la verdad de los vencedores, para justificar el porqué detentaban el poder. El crítico no duda, para definir el papel del cronista, en hacer uso de la etiqueta gramsciana de "intelectual orgánico». Si sus crónicas suponen, en más de un aspecto, el

- M. ' Rosa Lida de Malkiel, «El moro en las letras castellanas», Hispanic Review, 28 (1960), pp. 354-5. Véase más ampliamente en Amelia garcía-Valdecasas, «La singularidad de la frontera granadina según la historiografia castellana», La Crónica, 16:2 (1988), pp. 101-109.

'Gran crónica de Alfonso XI, ed. Diego Catalán, 2 vols., Madrid, Gredos, 1977, I, p. 205 (cit. en adelante como $\mathrm{GCA}^{\circ} \mathrm{XI}$ ).

"Diego Catalán, Un prosista anónimo del siglo XIv. La "Gran Crónica de Alfonso XI". Hallazgo, estilo, reconstrucción, Universidad de La Laguna, 1955. 
retrato del estamento nobiliario castellano, la presencia en ellas de elementos maurofilicos no resultará menos significativa".

La intención didáctica, la ostentación de presunta objetividad, la sequedad de estilo del Canciller, hacen muy distinto el texto que seleccionamos de entre sus cuatro crónicas, la Crónica de don Pedro I, del anterior, la Gran crónica de Alfonso XI. La guerra fratricida (1354-1369) y la guerra con Aragón (1357-1364), el relato de cuyos eventos esenciales constituye el esqueleto de la citada crónica elegida, se prestaban en principio bien poco a la manifestación de comportamientos corteses y al embellecimiento literario. La influencia de la literatura caballeresca en él es patente, desde el momento en que comparte con Froissart la idea de que los episodios de armas debían ser el tema principal de la literatura cronística. Su obra histórica se sitúa, por tanto, en el terreno, común con la ficción o seudo-ficción, del interés prioritario por cantar las proezas guerreras.

Puesto que la forma más concreta y permanente de plasmación del esfuerzo bélico en la Península, pese a temporales desplazamientos o alejamientos, se continuaba presentando en Granada, el conflicto entre moros y cristianos dará pie a algún aprovechamiento en este sentido (especialmente, en los capítulos del fracasado intento de toma de Antequera por don Pedro, en 1361 (cap. 7), o, aunque ya en 1394, en el quijotesco desafio de don Martín Yáñez de Barbudo, maestre de Alcántara (caps. 8-10). De todos modos, la remisión en el empeño bélico contra los moros, daría pocas oportunidades al lucimiento en ese tema, y el espíritu caballeresco de Ayala se manifestaría mejor en la acumulación de grupos nobiliarios, la admiración por las actitudes caballerescas de -o hacia - personajes como Du Guesclin o el Príncipe Negro, y la descripción de algunas - escasas - fiestas y desfiles, $y$, sobre todo, de fastos en el vecino reino francés ${ }^{10}$.

Entre la muerte de Alfonso XI ante Gibraltar y la vuelta a la guerra iba a correr un largo lapso de tiempo sin que tuviesen lugar campañas de entidad contra el reducto de Granada. El hilo de la reconquista seria reanudado por el regente don Fernando, aprovechando el crédito concedido por las Cortes al recién malogrado Enrique III. La primera etapa de la regencia fernandina (1407-1410) estará dominada por el rearme y la ofensiva castellanas, que culminarian en la toma de Antequera. La campaña exigió la movilización de enormes recursos para levantar tropas y organizar servicios $y$, por supuesto, ese gran esfuerzo no contó con las simpatías de muchos

- M. Garcia, Obra y personalidad del Canciller Ayala, Madrid, Alhambra, 1983, pp. 1667. Véanse, para la definición de "intelectual orgánico", sus conclusiones, esp. p. 323.

10 Ibidem, pp. 185-202. Seguiremos la ed. más conocida de Cayetano Rosell, "Crónica de don Pedro I", en Crónicas de los Reyes de Castilla, Madrid, BAE, Rivadeneyra, 1875 (cit. en adelante como $\mathrm{Cr} P$ I). Hay ed. critica de la misma, Crónica del rey don Pedro, ed. Constance L. Wilkins y Heanon M. Wilkins, Hispanic Seminar of Medieval Studies, Madison, 1985. 
grupos sociales. El saldo final de la guerra, con todo, fue claramente favorable, elevó enormente el prestigio del regente y significó el último intento organizado de conquista hasta que ochenta años más tarde, el nieto homónimo de Fernando de Antequera emprendiera la campaña definitiva. Los acontecimientos de esta primera guerra del siglo xv contra el reino de Granada están perfectamente plasmados por la pluma exacta y profesional del cronista oficial, Alvar García de Santa María ${ }^{11}$.

La Crónica de Juan II abrirá un periodo que contrasta con la escasez de los cuatro reinados anteriores. Se trata de una de las crónicas medievales más pormenorizada y concienzudamente escrita que han llegado hasta nosotros. Su primera parte hace el seguimiento de los últimos años de la vida de Fernando de Antequera, incluso trasladando el relato, a raíz de su coronación, al reino de Aragón. Después de un paréntesis de tiempo para el que sólo conservamos anotaciones dispersas (1417-9), la crónica se muestra enormemente objetiva sobre los hechos del reinado de Juan II (su contrapunto partidista lo tenemos en la Crónica de don Álvaro de Luna). Tanto es así que se ha llegado a sospechar que el abrupto abandono del cometido del cronista, en 1434, podría haber obedecido a la censura del valido del monarca.

Los Hechos del Condestable don Miguel Lucas de Iranzo constituyen uno de los textos cronísticos del reinado de Enrique IV que mejor reflejan las relaciones caballerescas entre moros y cristianos. Aunque la crónica sola-

"Para la figura literaria de Alvar García, y las cualidades literarias de su prosa, todavia poco estudiadas, véanse Amador de los Ríos, Historia crítica de la literatura española. VI, pp. 210-23, y Francisco Cantera Burgos, Alvar Garcia de Santa Maria y su familia de conversos. Historia de la judería de Burgos y sus conversos más egregios, Madrid, C.S.I.C., 1952, esp. pp. 230-37. La Crónica de Juan II de Castilla de Alvar Garcia de Santa María consta de dos partes: la primera abarca de 1406 a 1419 , y la segunda de 1420 a 1434 . La primera parte ha sido editada críticamente (aunque sólo los años 1406-1411) por Juan de Mata Carriazo, Crónica de Juan II de Castilla, Madrid, Real Academia de la Historia, 1982 (citada en adelante como AGSM). Para los años restantes de esta primera parte (1411-1419), contamos tan sólo con la selección de Donatella Ferro, Le parti inedite della "Crónica de Juan II" di Alvar Garcia de Santa Maria, Consiglio Nacionale delle Recerche, Venezia, 1972 (citada en adelante como $A G S M$, part. ined.). La segunda parte (1420-1434) fue editada, a partir de la copia del ms. original, por Antonio Paz y Meliá, en los vols. 99 (pp. 79-465) y 100 (pp. 3-409) de la Colección de documentos inéditos para la Historia de España, Madrid, 1891 (si bien con múltiples deficiencias). No debemos confundir estas dos partes de la original Crónica de Alvar García, con la que Galíndez publicó en 1517, recogida por Cayetano Rosell en sus Crónicas de los Reyes de Castilla. II (B.A.E., LXVIII), pp. 273-695, verdadera Refundición de la anterior. La invalidez del texto como original ya fue puesta de manifiesto por Inez Macdonald, «A Coronation Service, 1414", Modern Language Review, XXXV, n. 3 (julio, 1941), 351-68, esp. pp. 351-4, y luego ratificada por Cantera Burgos, Alvar Garcia, pp. 224 y B. Sánchez Alonso, Historia, pp. 303-5. Lore Terracini ha alzado una defensa en pro de la coherencia de Galíndez y de la posibilidad de que Pérez de Guzmán, o algún otro historiador, antes que el propio Galíndez, pudiese haber realizado ya la refundición que tal vez él se habria limitado a editar ("Intorno alla Crónica de Juan II», Studi Romanzi, XXXIII (1961), pp. 7-151, y esp. pp. 26-55). 
mente cubre el periodo que va desde 1458 hasta 1471 , es decir, trece años de la vida del condestable, y aunque se trate de una crónica biográfica, y no una crónica real, resulta ser, como dice su editor, Juan de Mata Carriazo, "una ventana abierta sobre la vida de un noble y una ciudad fronteriza de Andalucia en los tiempos calamitosos de Enrique IV. Su misma escasez de arreos literarios, su tono doméstico y un poco ramplón garantizan sinceridad y exactitud: como que su elocución suele quedar tan lejos de la epopeya que casi no sale del cuadro del género»" ${ }^{12}$.

Miguel Lucas, alcaide de Jaén, es el mejor representante de las contradicciones de la vida en la frontera de Granada. Siendo el mayor interés de la obra de descripción de la vida cotidiana y de las costumbres sociales, especialmente fiestas, no será extraño que nos aparezcan notas interesantes sobre la reciprocidad de influencias entre moros y cristianos en la vida de frontera y sobre la adopción de costumbres y hábitos culturales moriscos en la zona castellana. Fiestas de todo tipo, coincidiendo con las festividades religiosas principales del año, son descritas con gran lujo de detalles sobre vestidos, manjares, adornos, desfiles... ${ }^{13}$. Este aspecto es complementado por el político y militar, en concreto por el relato de los incómodos incidentes de frontera. De manera que en los Hechos del Condestable tenemos la oportunidad de complementar los aspectos pacíficos con los bélicos en una singular dialéctica de rechazo/aproximación al enemigo musulmán.

Finalmente, la Crónica de los Reyes Católicos de Diego de Valera, continuación de su Memorial de diversas hazañas, dedicado al reinado de Enrique IV, aunque quedó interrumpida en 1488 por la muerte del autor, cubre en su primera parte los episodios de la guerra de Portugal y, en la segunda y más importante, los de la guerra de Granada. Caballero andante y polígrafo, consejero y procurador, legislador y poeta, viajero y justador, este "gran hablistán y parabolano», como le llamaba Juan de Valdés, fue testigo activo de los reinados de Juan II, Enrique IV y los Reyes Católicos. El autor

12 Hechos del Condestable don Miguel Lucas de Iranzo, ed. Juan de Mata Carriazo, Madrid, Espasa-Calpe, 1940 (cit. en adelante abreviadamente como Hechos). El editor atribuye la autoria de la obra a Pedro de Escavias, atribución que segirá J.B. Avalle-Arce, El cronista Pedro de Escavias, una vida del siglo XV. The University of North Carolina Press, Chapel Hill, 1972. Sin embargo, Michel Garcia, en su ed. de Pedro de Escavias, "Repertorio de príncipes de España" y obra poética del alcaide Pedro de Escavias, CSIC y Diputación Provincial de Jaén, 1972 , se opone razonadamente a tal atribución, proponiendo una doble autoría: la del secretario del biografiado, Luis del Castillo, más, a partir de 1466, la de su sucesor en el cargo, Juan de Olid, que terminaría la obra para que sirviera a los hijos del condestable como reivindicación nobiliaria.

${ }^{13}$ Para los motivos de las fiestas, véanse los artículos de Charles V. Aubrun, «La Chronique de Miguel Lucas de Iranzo», en Bulletin Hispanique, XLIV (1942), pp. 81-95; F. Very, «A Fifteenth-Century Spanish Easter Egg Combat and Some Parallels", Romance Notes, IV. 1 (1962), pp. 66-69; y, más recientemente, J. Oleza, «Teatralidad cortesana y teatralidad religiosa. Vinculaciones medievales", en Ceti sociali ed ambienti urbani nel teatro religioso europeo del '300 e del '400. Centro studi sul medioevale e rinascimentale, Viterbo, 1985. 
del Espejo de verdadera nobleza tenía una visión particular, a un tiempo que orgánica, respecto de su tiempo ${ }^{14}$.

A partir de estas cinco crónicas vamos a tratar de describir y analizar, en primer lugar, el común ideario caballeresco de cristianos y musulmanes, a través de elementos como la alabanza del enemigo y la exaltación de los valores de la lealtad, valor, honra, fama y amor. A continuación, examinaremos la presentación que hacen las crónicas de la infiltración de lo morisco en el estilo de vida cristiano, a través esta vez fundamentalmente de costumbres, juegos, fiestas y modas en el vestir. Estos aspectos nos servirán para trazar unas conclusiones sobre la relación entre la maurofilia y el ideal caballeresco de la sociedad castellana tardo-medieval.

\title{
2. IDEAS CABALLERESCAS COMUNES A MOROS Y CRISTIANOS
}

\subsection{Exaltación del moro caballeresco}

El cronista de Alfonso XI exalta la dinastía de los reyes de Benamarín, elogiando a todos los de este linaje:

\begin{abstract}
«este rrey Abdalfaque fue el primero de los marines, e fue buen rrey en su ley e muy esforçado e dio çima a grandes fechos, e llamaronle los moros esmeril de los rreys, que quiere dezir espejo de los rreys; e avn, segund dize la Grande Ystoria de Africa, fue llamado rrey santo, e esto fue por que en su vida nunca fue vencido el ni los suyos... E el rrey Aboyuçafe ... fue buen rrey en su ley ... su hermano Aboxafia ... fue buen rrey. $E$ bien anssi fueron todos los otros rreyes muy buenos que descendieron deste linagem (GCA ${ }^{\circ} \mathrm{XI}, \mathrm{II}$, p. 201) ${ }^{15}$.
\end{abstract}

Y también elogia al rey Albohacén, sus cualidades, su caballería, con motivo de su subida al trono de Benamarín tras la muerte de su padre el rey Alboçayde:

14 Diego de Valera, Crónica de los Reyes Católicos, ed. Juan de Mata Carriazo, Revista de Filología Española, Anejo 8, Madrid, Centro de Estudios Históricos, 1927 (cit. en adelante como Valera).

is Para el concepto de santidad, cfr. El Victorial. Crónica de Pero Niño, Conde de Buelna. Por su alférez Gutiérrez Diez de Games, Madrid, Espasa-Calpe, 1940, donde el autor propone ya una asociación entre el concepto de la victoria militar, mundana, y la victoria espiritual, a partir de una original concepción de la caballería cristiana (pp. 38-9 y 44-5). De igual modo, Fernando de Antequera será llamado "caballero de Jesucristo" por Alvar García (AGSM, cap. 189, p. 399). 
«el buen rrey Alboaçen ... fue vno de los rreyes moros el mejor que nunca sobio en cauallo nin tomo azagava en mano. E en el comienço del su rreynado se fizo dudar a los suyos e a los christianos, anssi que de luengas tierras temien la su lança e presçiauan la su caualleria; e con gran saber se fizo amar a los suyos $e$ se apodero de los sus rreynos como nunca fue rrey en la partida de Africa hasta en aquel tiempon ( $G C A^{\circ} \mathrm{XI}, \mathrm{II}, \mathrm{p} .208$ ).

El cronista alfonsí exalta también la actitud ejemplar del rey Albohacén, quien, al conocer la muerte de su hijo el infante Abomelique, mostró gran entereza ante sus caballeros: "salio de la su camara demostrando grande plazer e dando a entender que non auia pesar nin duelo, como quier que no pudo ser que todos non entendiesen su gran manzilla» (II, p. 287). Es el mismo gesto caballeresco, gélido y altivo, que, en la campaña contra Setenil, Alvar García de Santa María destacará en Pero Afán de Ribera, adelantado mayor de Andalucia, cuando igualmente recibe la noticia de la muerte de su hijo y heredero don Rodrigo: "E el adelantado mostró muy poco sentimiento de la muerte de su hijo, no porque él no la tenia en la voluntad, mas por mostrar que él muriera bien" (AGSM, cap. 77, p. 173).

La narración de la victoria de don Juan Manuel, en 1326, sobre el ejército moro contiene un elogio de Ozmín, caballero granadino: "vn cauallero bueno armado de sus armas cabdillo de los moros -e si me alguno preguntase quien era, yo le diria que fue Ozmin, el buen moro» (I, p. 388); y asimismo elogia la caballería de Alicazar en el encuentro que tuvo el ejército del infante Abomelique, cuando se hallaba corriendo la frontera, con el ejército cristiano: "e aquel moro ynfante Alicazar adereço a el a guisa de buen cauallero a marauilla ... se defendia atan marauillosamente que todos aquellos que lo veyan se hazian marauillados» (II, pp. 279-80).

Una nueva alabanza del linaje de los reyes de Benamarín aparece en las palabras que el rey de Granada dirigió a su aliado, el rey Albohacén de Benamarín, para animarle a la batalla contra los reyes de Castilla y Portugal en Tarifa:

"Rrey Alboaçen, moros e christianos por todo el mundo saben que en todo el non a mas acabado rrey de lo que vos sodes ... E deuessevos de menbrar como sodes acabado de linaje, e de la alta sangre do vos venides; e membresevos del rrey Abdalfaque quan acabado rey fue en la su vida, e el rrey Abojuçaff su hijo ... e como christianos e moros lo tienen puesto en libros por las bondades que hizo» (GCA ${ }^{\circ} \mathrm{XI}, \mathrm{II}$, p. 400$)$.

De estas palabras del rey granadino se desprende la consideración de la 
honra como un concepto hereditario. Por lo tanto, si un caballero la gana, la transmitirá a sus descendientes, que deberán esforzarse por conservarla.

La exaltación del adversario moro en esta crónica se produce también cuando es derrotado porque, como afirma Diego Catalán, el cronista alfonsí "sabe bien que la gloria del enemigo vencido revierte sobre su vencedor" ${ }^{16}$. Por lo tanto, incluso el moro vencido inspira la simpatía del cronista, como sucede cuando al narrar la batalla del Salado ensalza al máximo las figuras de los moros muertos: "fueron muertos fasta trezientos moros muy honrrados, señores de tierras e caudillos de grandes conpañas; e con estos murieron grandes cauallerias de moros" (II, p. 434); o en el episodio, señalado por Diego Catalán, en que el infante Abomelique, vencedor de cristianos, fue encontrado muerto, inspirando compasión: "assi yacia desamparado e vilmente que no havia home que lo viesse que del no oviesse duelo, como quier que fuese moro ${ }^{17}$; o cuando al narrar la derrota del ejército moro por el infante don Pedro en el castillo de Alicún, se refiere a los moros derrotados con una serie de epítetos que les califican positivamente: «buen moro Ozmin ... mill e quinientos cavalleros moros honrrados de grande cuenta..." (I, p. 297). Y no sólo el cronista alfonsí elogia al moro vencido. También Diego de Valera relata cómo el propio marqués de Cádiz honró a los moros vencidos de Zahara: "El Marqués los llevó consigo a Marchena, e les fizo honrra»" ${ }^{18}$.

Pero también la gloria del vencedor revierte sobre el vencido. Así lo observa el rey de Granada, en su discurso a Albohacén, al referirse a la batalla de Tarifa: «si vos fueredes vençido, vençervos a vno de los nobles rreyes que grand tienpo a que fue en christianos" (II, p. 401). Y el propio Albohacén lo reconoce cuando, tras la victoria cristiana en el Salado, huye a Gibraltar y alli, delante de sus hombres, ensalza la figura del vencedor; «que esto no era marauilla en el ser vençido por mano del rrey don Alonso de Castilla, que era vno de los mas honrrados e de los mas altos principes que auie en las tres partes del mundo" (II, p. 435).

También se ensalza la bondad en los moros. Así, Diego de Valera se refiere a la de Afanete tras la conquista de Málaga por los Reyes Católicos:

\footnotetext{
16 Diego Catalán, «Ideales moriscos en una crónica de 1344», Nueva Revista de Filologia Hispánica, 2 (1953), p. 575.

${ }^{17}$ Ibidem, p. 576.

18 Diego de Valera, Crónica de los Reyes Católicos, p. 177. La primera parte de la Crónica de Valera guarda una dependencia respecto a las Décadas de Alonso de Palencia. Pero más notable y todavia indescifrable es la relación de práctica identidad de muchos capítulos de su segunda parte con otro texto, La Historia de los hechos de don Rodrigo Ponce de León, marqués de Cádiz (ed. del Marqués de la Fuensanta del Valle, Colección de Documentos Inéditos, n. ${ }^{\circ}$ 106), a la que nos hemos de referir infra. hasta el punto de que resulta dificil discernir a ciencia cierta qué obra influyó en qué otra. Un minucioso estudio comparativo entre ambas fue efectuado por Carriazo, en su ed. de Valera, Crónica de los Reyes Católicos, pp. CXL-CLIII.
} 
' "fueron presos por mandado del rey el alguazil Zegri e su sobrino llamado Afanete ... este Afanete era muy buen moro, e paresçio su bondad porque el dia que salieron a dar en las estancias este venia delante de todos a cavallo, hablava bien ladino, e topo con unos moços christianos que andavan en la Rivera, e mandoles que fuyesen sin hazerles ningund dañon (Valera, p. 270).

\subsection{Lealtad y traición}

El autor de la Gran crónica de Alfonso XI señala como cualidad fundamental del caballero, tanto moro como cristiano, la lealtad hacia su rey, símbolo de la patria, hallándose en la narración cronística numerosos testimonios de esta concepción, como por ejemplo en el episodio en que los moros de la ciudad de Teba, ante el ataque de Alfonso XI, la defendían denodadamente, "sufriendo gran trabajo por guardar verguença e lealtad, que todos los omes son tenudos de guardar, e atales fueron los moros desa vegada por ganar honrra e prez, que oluidaron la muerte e estuvieron en aquel lugar a guisa de buenos» (I, p. 484); y cuando el rey Aboamó de Tremecén pidió ayuda financiera a un alguacil para pagar a sus vasallos durante el cerco a Bugía, perteneciente al rey de Túnez, el cronista exalta la lealtad en la respuesta del alguacil, más preocupado por la honra de su rey que por su propio dinero: "E el alguazil leal no fue cobdiçioso, e dixo al rrey que le seruirie de grado con el cuerpo e con lo que toviesse, e mas presçiaua el la su honrra e estado de su rrey natural e señor que aver toviesse, e prometiole que le darie tanto auer con que pudiese pagar su hueste dos años» (II, p. 217).

$\mathrm{La}$ lealtad debe estar por encima de las rivalidades que separan a moros y cristianos, y por eso Pero López de Ayala condena la codicia del rey Pedro I, que le llevó a dar muerte al rey Bermejo durante una cena en Sevilla, acción que fue desaprobada por los cristianos: "e por la cobdicia de la joyas que el rey Bermejo trujo, fue su muerte ... empero todos lo tovieron por non bien fecho, e les ploguiera que el Rey non lo ficiera asi' ${ }^{19}$.

En cuanto a los actos de traición, el cronista alfonsí los critica hasta el punto de desear la condenación eterna a quien los cometa, juicio que, como ha observado Diego Catalán, lleva implícita la posibilidad de salvación para un buen musulmán ${ }^{20}$. El cronista critica la traición de los hijos de Ozmín, que asesinaron al rey de Granada:

19 Ayala, Cr PI, p. 519. Cfr. El Victorial, que en su curioso "Cuento de los Reyes» ofrece un ataque todavía más feroz contra el monarca asesinado (pp. 48-9).

${ }^{20}$ Diego Catalán, «Ideales moriscos", p. 577. 
"Abraen tiro vn espada de la vayna e firio al rrey con ella; e bien ansi lo fizieron los otros cavalleros traydores a Dios y al mundo, los que mal siglo ayan sus animas... E por esta trayçion que fizieron los moros de Granada en matar a su rrey e su señor, fue la casa de Granada tirada de su honrra e drerribada del su estado e los moros mal andantes e las tierras non ouieron sombra segund que antes auian" (II, pp. 71-72).

Y también juzga severamente la traición del infante Aboali a su padre el rey Alboçayde:

"consejeros malos que el auie que le aconsejaron que tomase los thesoros del rrey su padre e se alçase con la villa e se llamase rrey de Fez; la qual cosa hizo el infante no guardando a Dios ni guardando a su padre lo que deuia ... e paso el natural deudo que los fijos son naturalmente de guardar a su padre” (II, p. 202).

Y la del infante Botexefin hacia su padre el rey Aboamó, asesinado por haberse negado a prestar ayuda económica a su hijo para sostener el cerco de Bugía: "entro en el el pecado e hizole comedir como matase al rrey su padre. E ansi lo hizo el traydor, que sea perdido con Judas en el ynfierno" (II, p. 219). Pero Botexefin, a pesar de haber traicionado a su padre, merece la lealtad de sus vasallos, moros y cristianos, por lo tanto el que le traicione, como el alguacil Muza Benahalí, merece la muerte. Tras la conquista de Tremecén y la muerte del rey Botexefin por el ejército del rey Albohacén de Benamarín, el cronista comenta cómo murieron:

"otros muchos e muy buenos caualleros vasallos de aquel rrey malauenturado, e murieron todos delante del como buenos faziendo lealtad, la qual moros y christianos son todos tenudos a fazer delante los sus señores. $E$ en aquel lugar murio Muça Benahali muerte mala e vil como traydor que le hizo dar el rrey de Benamarin" (II, p. 235).

El incumplimiento de las promesas hechas por cristianos a moros es también objeto de crítica, como cuando el infante don Pedro rompió las treguas que había acordado con el rey de Granada, faltando así a su palabra y a "la fe e la fieldad que Dios establesçio entre los omnes en comunalmente» (I, p. 309); o la falta de lealtad de algunos caballeros que no respetaron la libertad dada por el rey Fernando el Católico a los moros de Coín, con motivo de la rendición de la plaza, causando el enojo del rey: 
«por ser de noche e llovía mucho, algunos ovieron lugar de salir del real e tomaron algunos moros; de que el rey ovo muy grand enojo, e mandó luego degollar dos escuderos que avian ydo contra su mandamyento, e mandó recoger todo lo que era tomado para lo restituyr a los moros» (Valera, p. 188).

\subsection{Valentía}

La exaltación del moro como guerrero se encuentra ya en el Libro de los estados de don Juan Manuel ${ }^{21}$ y en la Gran crónica de Alfonso XI, cuyo autor reconoce que "los moros eran muy maestros en las peleas» (II, p. 62). El cronista alfonsí, Alvar García de Santa María, el autor de los Hechos del Condestable y Diego de Valera elogian la valentía del adversario moro durante el combate en diversos pasajes de sus crónicas.

En la crónica alfonsí se alaba el valor de granadinos y marroquies en múltiples ocasiones, por ejemplo, en el enfrentamiento de dos reyes hermanos marroquíes, el de Sujulmencia y el de Benamarín: "como quiera quel rrey de Sujulmençia mostro grand bondad a los golpes primeros, mas esto fue muy poco, ca la bondad de su hermano el rrey Albohacen le hizo dexar el canpo mal su grado" (II, p. 211); e igualmente los infantes Abomar y Abomelique, hijos del rey de Benamarín, mostraron "gran bondad e gran proeza en armas» durante el cerco de Tremecén (II, p. 233).

El cronista ensalza también la valentía de los moros en sus encuentros con los cristianos, como el que tuvo lugar en la villa de Siles que concluyó con la victoria cristiana, a pesar de que los moros estuvieron "muy firmes en la pelea" (II, p. 267); o en la derrota que sufren en Arcos: "e los moros como omes de gran esfuerço, maguer que vian caer y morir muchos de los suyos, non querian partirse de la pelea ni procurauan de fuyr; e estauan firmes firiendo los christianos lo mas fuerte que podian" (II, p. 275); o durante la batalla del Salado, cuando el infante Aboamó, mandado por su padre el rey Albohacén, presentó batalla al ejército cristiano al cruzar un río en su marcha hacia el Salado:

«E tan rrezio e tan denodadamente llego el ynfante Aboamar con su gente a ferir en aquellos caualleros christianos, que por fuerça de armas e por bondad de caualleria les hizo perder tierra e boluer contra do estaua la delantera del rrey don Alonso de Castilla» (II, pp. 427-8).

${ }^{21}$ Don Juan Manuel, Libro de los Estados, ed. Robert B. Tate y Ian R. Macpherson, Clarendon Press, Oxford, 1974, p. 146. 
La reñida batalla del Salado es ocasión para equiparar a moros y cristianos en cuanto al valor: "los moros començaron la pelea con ellos muy rreziamente, pero los christianos los acometieron a guisa de muy buenos caualleros» (II, p. 432). La valentía de cristianos y moros granadinos es puesta de ejemplo por el rey de Granada al rey Albohacén de Benamarín con motivo de la mencionada batalla:

\begin{abstract}
"e tomad enxenplo de aquestos rreyes christianos, que non tienen la terçia parte de la caualleria que vos tenedes, e vienen todos con alegres coraçones por tomar muerte ... e tomad exemplo en los rreyes de Granada, que ... con muy poca de caualleria se deffienden de quantos christianos ay en Europa ... e sienpre Granada con su poca caualleria queda honrrada por su buena ventura e bondad de los suyos" (II, pp. 400-1).
\end{abstract}

En una carta escrita por Alfonso Fernández de Cantalles, hallamos un elogio de los moros defensores de Antequera: "non avia omnes synon vallesteros buenos e denodados e escogidos e verdaderos con muy gran lealtança e cordura, los quales de sy nunca dieron mengua a ley de omes e por tales son oy en este real loados" ${ }^{22}$. También el autor de los Hechos del Condestable pone de manifiesto la valentía de los moros al narrar el ataque a Montejicar por el Condestable don Miguel Lucas de Iranzo y don Alonso de Aguilar: "sesenta o setenta escuderos moros, muy buenos ... los quales defendian bien la dicha fortaleza, y matauan e ferian asaz" ${ }^{23}$. Y Diego de Valera exalta la valentía del adversario moro al narrar las sucesivas conquistas que realizó el marqués de Cádiz: Alhama Benamaquez, Ronda, Loja, etc.: "los moros ... se defendieron valientemente" (Valera, p. 139), "los moros pelearon muy bien" (p. 187), "los moros valientemente defendian" (p. 190), "los moros valientemente pelearon" (p. 203). En la toma de Alhama, el marqués de Cádiz, aconsejado por sus hombres de abandonar la empresa, les puso de ejemplo el valor de los moros: "debian mirar cómo aquellos moros querian morir por defender su honrra e fazienda e libertad, e que asi lo devian él y ellos fazer por lo que tocava a sus honrras" (Valera, p. 138).

En esta crónica hallamos otra equiparación del valor de moros y cristianos al referir la conquista de una parte del arrabal de Vélez Málaga: "[los moros] peleavan valientemente de continuo defendiendo su cibdad; e los christianos no menos hazian, matando y feriendo en ellos quantos podian" (Valera, p. 221); y al narrar el cerco de Málaga, el cronista comenta varias

${ }^{22}$ Luis Suárez Fernández, «Juan II y la frontera de Granada», Cuadernos de Historia Medieval, 2 (1954), pp. 5-47; nos referimos en concreto a p. 12, n. 29.

${ }^{23}$ Hechos del Condestable, p. 464. 
veces lo bien defendida que estaba la ciudad por los moros, los cuales «defendianse tan bravamente que los christianos ... no podian ganarles" (Valera, p. 239), e incluso cuando el ejército cristiano tomó las torres del muro del arrabal, "los moros trabajaron mucho por las recobrar ... e todo aquel día los moros pelearon muy bien" (Valera, p. 244). Durante el asedio de Málaga, el rey Fernando pudo observar "cómo los moros tan valientemente se defendian e la forma que tenian en reparar cualesquier daños que recibian" (Valera, p. 254).

El ánimo o esfuerzo es otra de las cualidades propias del caballero, y tiene especial importancia durante los combates, por lo que los granadinos, durante el cerco cristiano a la ciudad de Teba, acudieron para animar a los sitiados: "Ozmin e los moros del rreyno de Granada ... vinieron al rrio, por mostrar esfuerço, por que los moros de la villa de Teba no desmayasen ni cuydasen que avia perdido el acorro" (GCA $\left.{ }^{\circ} \mathrm{XI}, \mathrm{I}, \mathrm{p} .483\right)$, y el rey de Granada también acudió a Gibraltar para animar a los moros de Benamarín, Túnez y Marruecos: "por los esforçar más» (AGSM, part. ined., p. 218). Igualmente, durante el cerco cristiano a Vélez, el rey de Granada, que había prometido ayuda a los sitiados, les envió "çinco moros con cartas a la cibdad ... e por ellas paresçía como su rey les enbiava a dezir que se esforçasen $e$ fiziesen como buenos e leales" (Valera, p. 227). Diego de Valera califica de "esforzado" al rey de Granada cuando en 1482, al recibir la noticia de la derrota de su ejército por el de Pedro Vargas, alcalde de Gibraltar, y desoyendo los consejos de sus caballeros de abandonar la lucha, él decidió continuarla en aquel lugar, porque "el rey era cavallero esforçado, dixo que no ... dexaría la cavalgada sin pelear" (Valera, p. 118), y el mismo rey de Granada dice de su adversario Pedro Vargas «tan buen cavallero y tan esforçado» (Valera, p. 119).

\subsection{Honra y fama}

Estos dos conceptos se hallan intimamente ligados a la victoria en el combate. Así lo expresa el cronista alfonsí cuando, con motivo de la batalla de Tarifa, el rey de Granada habla a su aliado el rey Albohacén de Benamarín sobre la necesidad que tiene el guerrero de ganar fama en la lucha:

E por esto, Señor, vos non querades perder vuestro buen prez e fama, que los vuestros anteçessores ganaron e vos otro tal desque rreynastes, por ninguno que vos ponga estos miedos; e non creades a los que vos aconsejan que vos tornedes para Algezira en antes que tomedes esta villa sobre que yazedes; e en este lugar vos acabe fama e honrra para siempre, o perdida o deshonrra por tiempos del mundon (GCA ${ }^{\circ} \mathrm{XI}, \mathrm{II}$, p. 400). 
Y antes de comenzar la batalla, el rey Albohacén se dirigió a sus caballeros hablándoles del incentivo que constituía para el combate la consecución de la fama y la honra: "bien sabed, que si oy aqui fuere vençido el rrey don Alonso e los christianos que con el vienen, que nos somos los mas honrrados e mas bienauenturados omes que nunca fueron ni seran, e por esta batalla podemos auer honrra e fama de que fablen por sienpre» (II, p. 424). Por tanto, la derrota significa la deshonra. El ejército cristiano mandado por don Juan Manuel, consciente de que su victoria sobre Ozmín, en agosto de 1332, supuso para el caudillo moro la pérdida de su honra, acudió a Guadalferez "cuydando que Ozmín saldría contra ellos a vengar su desonrra» (I, p. 389). La llegada del rey de Tremecén hasta Teza, en guerra con el rey de Benamarín, significó para éste su deshonra y la de todo su linaje, pues siempre habían vencido a sus adversarios: "por deshonrra de los reyes de Benamarin... e que les pesase de tales fechos como estos, e que non quisiessen que la casa honrrada de Benamarin resçibiesen deshonrra de rreyes que en el mundo fuessen» (II, p. 229). La perspectiva de una victoria cristiana preocupó a Mahomad, rey de Granada, cuando cercó Castro con ayuda del infante Abomelique, pues Martín Alonso y algunos cordobeses se dirigieron a defenderlo y "el rrey de Granada rresçelose que pues... rresçibiria dellos daño e deshonrra» (II, pp. 25-26).

La falta de certeza en la consecución de una victoria, y por tanto la posibilidad de una deshonra, es la causa de que don Clarife el alárabe advierta al rey Albohacén de la inoportunidad de luchar contra los cristianos en Tarifa, pues la ocasión no era muy favorable para los moros, por lo que rogó al rey "non desçender de la honrra en que Dios vos puso", teniendo en cuenta que los cristianos acudian a la lucha con alegria y decisión, «los rreyes por auer la honrra y las otras gentes por auer fama", y le aseguró que si seguía su consejo "hareis como rrey de gran saber, e auredes honrra con prouecho, e tornaredes allende el mar con la mayor honrra que rrey torno" (II, pp. 398-99). Contrariamente, el rey de Granada argumentó a Albohacén la necesidad de luchar contra los cristianos por Tarifa, refiriéndose a la honra como un concepto hereditario: "deuedes hazer mucho por levar vuestra honrra adelante» (II, p. 400). Una vez finalizada la batalla de Tarifa con la derrota mora, el rey Albohacén, solo ante su consejero Clariffe, se lamentó profundamente de su suerte, "llamando se rrey catiuo e astroso e amenguado de bien e de honrra» (II, p. 435).

La honra es esencial para el caballero, por tanto el concederle un valor inferior a los bienes materiales es criticado por Pero López de Ayala a través de la carta que el sabio moro Benahatín envió al rey don Pedro de Castilla; "hay omes que presçian sus algos más que sus honras" (CrPI, p. 569), y esto conduce al cronista a criticar la codicia, llegando a poner como ejemplo la conducta de Jesucristo: "El Dios que dicen los sabidores de los christianos que se vistió en carne e en figura de ome por los salvar, non ovo ninguno que 
más arredràdo fuese deste pecado que él fue en el tienpo que paresçió en carne» (CrPI, p. 569; cfr. tb. p. 593).

La muerte de un príncipe por su pueblo le conferirá honra, y así lo expresa el rey Albohacén ante los ciudadanos de Benamarin, al conocer la muerte de su hijo, el infante Abomelique, que murió "por la honrra e estado de Benamarín e de la su casa, que sienpre fue muy onrrada en vida de los nuestros anteçessores... E... por honrra de la nuestra ley» $\left(\mathrm{GCA}^{\circ} \mathrm{XI}, \mathrm{II}, \mathrm{p}\right.$. 288).

\subsection{El amor}

En el amor caballeresco que el cronista de Alfonso XI atribuye al moro granadino y africano se encuentra un antecedente de lo que más tarde aparecerá en el Romancero morisco. Y este ideal caballeresco se muestra especialmente en el discuro del rey Albohacén que, durante la batalla de Tarifa y ante la opinión de Bomandiche de enviar a Algeciras a mujeres y niños para ponerles a salvo de la batalla, hizo una apología del amor y del caballero enamorado:

«...bien sabien todos quantos esfuerços de cauallerias buenas fazian los omes por amor de las mugeres, lo vno con amor que les fuerça e les da gran ardimento pora pelear viendo do ellas estan, e lo al que los que no son amados dellas hazen mucho que sean amados, e por esto oluidan tierras e viçios e pierden duelo de los cuerpos por hazer mas que otros onbres. E otrosy el que tiene muger e hijos querrialos deffender e hazer mucho por levar la honrra $\mathrm{e}$ lo mejor de aquel que la non touiere; que el que muger non tiene en tal lugar sienpre sospira por ella si la bien quiere, e si esta en batalla, el coraçon tiene en ella... E por eso, venga el rrey don Alonso de Castilla, que las mugeres no las enbiare a ninguna parte; enantes mando a todas quel dia de la batalla se apuesten todas muy byen como parescan a sus maridos e a los sus entendedores muy fermosas, e que ellos ayan coraçones para hazer todo bien por las deffender si atal tienpo viniere... E por esto las mugeres aqui quedaran, si yo aqui estuviere; e si fuere a otra parte, comigo yran; e si yo fuere el vençedor, ellas lo pasaran bien; e si nos fueremos vençidos o muertos, no auemos menester mugeres, e las que murieren yran salvas e hallarlas hemos connosco en la Casa Sancta del gran profeta Mahomad» (GCA'XI, II, pp. 396-7).

De este discurso, testimonio de superioridad del caballero enamorado, se desprende que la presencia de la mujer amada en el campo de batalla constituye un estímulo para el caballero durante la lucha. Esta costumbre, como ya ha señalado Diego Catalán, estaba extendida por muchos pueblos 
bárbaros ${ }^{24}$. No hay más que recordar el episodio del Cid cuando, estando en Valencia, se deleita con la idea de realizar alguna hazaña ante su mujer:

"créçem' el coraçón

con Dios aquesta lid porque estades delant;

yo la he de arrancar" ${ }^{25}$

\section{COSTUMBRES Y MODAS MORISCAS}

El influjo moro en la vida cristiana no se produce a raíz de un pacífica convivencia entre ambos pueblos, sino a lo largo de los siglos de lucha. Es un fenómeno de contacto de culturas. El carácter imaginativo e inclinado a la fantasía del pueblo español juega un papel primordial en la adopción de costumbres de vida morisca por los cristianos peninsulares, que se sintieron atraidos por el encanto estético de la civilización mora: la suntuosidad de la arquitectura y su perfecta combinación con la naturaleza, cuyo máximo exponente lo constituye la Alhambra, la riqueza y vistosidad de sus ropajes y juegos.

La moda del vestir a la morisca es anterior al siglo XV. Los nobles cristianos vestían la versión lujosa de la indumentaria mora como prenda de gala. Este uso de vestiduras moras en las fiestas fue un factor que contribuyó decisivamente a la creación de la imagen del moro cabelleresco sentimental, y sobre todo a la de su estilizado ambiente. Bernando del Carpio aparece "a la morisca vestido" en el romance "Con los mejores de Asturias", el Cid y sus caballeros visten prendas árabes («ricas aljubas vestidas / $y$ encima sus albornoces») en el romance "Por Guadalquivir arriba»"

Tenemos testimonios de que los nobles cristianos vestían prendas moras por el Libro del Passo honroso de Suero de Quiñones, la Crónica de Juan II y los Hechos del Condestable Miguel Lucas de Iranzo, crónica que ofrece un cuadro vivo de las fiestas "a la morisca", que tenían lugar en Jaén entre 1460 y 1471. En las descripciones que realiza el cronista de los juegos de caballería y espectáculos ofrecidos al aire libre emergen en diversas ocasiones elementos de estilo propiamente moriscos, tanto prendas de vestir, como en el juego de cañas, en que uno de los dos bandos adopta el papel de moriscos ataviados con ropas adecuadas. Cabe imaginar que estas fiestas

${ }^{24}$ Diego Catalán, «Ideales moriscos», p. 274.

2. Poema de Mio Cid, ed. Ian Michael, Madrid, Castalia, 1976, vv. 1655-56.

26 Ramón Menéndez Pidal, Flor nueva de romances viejos. Madrid, Espasa-Calpe, 1943. pp. 100 y 230 . 
no estuvieran restringidas al estrecho marco vital del Condestable, pues además se conserva un relato de viajes alemán de aquella época en que se cuentan las costumbres moriscas de Enrique IV en su forma de vida, y aparece también la descripción de un banquete en el patio de un castillo, en 1453, en el que se menciona la presencia de un gigante ataviado de morisco ${ }^{27}$.

El vestido y las costumbres morunas ejercieron una profunda influencia en la nobleza castellana y, especialmente, en Enrique IV. Con este rey, gran admirador de todo lo árabe, la moda se afianzó. Según el cronista Alonso de Palencia, Enrique IV ordenó vestir su estatua con indumentaria mora. Pero además de la moda en el vestir adoptó sus costumbres: sus comidas, su forma de sentarse, y su forma de cabalgar a la jineta. El inventario que se hizo del guardarropa de la duquesa de Alburquerque, en 1479, evidenció la posesión de marlotas, albornoces, zaragüelles, etc. Gómez Manrique, que murió hacia 1490, aparece tocado con un turbante en la estatua yacente de su sepulcro, conservado en el museo de Burgos.

\subsection{El juego de cañas}

El cronista de los Hechos del Condestable escribe que los caballeros de Jaén jugaban a las cañas "a la manera de la tierra» (Hechos, p. 66). Efectivamente, el juego de cañas era sentido como algo no de moros o de cristianos, sino común a ambos, propio de la tierra, que acabó por convertirse en el deporte más característico de la nobleza peninsular ${ }^{28}$. Las vestiduras moriscas eran las más apropiadas para jugar a las cañas, ejercicio "que exigía un completo dominio del arte de montar a la jineta ${ }^{29}$ y consistía en el enfrentamiento de dos bandos de caballeros que arrojaban las cañas. Constituía todo un espectáculo por la riqueza de prendas y arreos que se exhibían, así como por la "armonía y simbolismo de colores y emblemas»" que adoptaban los contendientes. Este deporte, por el derroche de lujo que le carac-

${ }^{27}$ Ulrich Knoke, Die spanische "Maurenromanze". Der wandel ihrer Inhalte. Gehalte und Ausdrusksformen zwischen dem Spatmittelalter und dem Beginn des Barock, Göttingen, Universität, 1966, pp. 29-30. Para descripciones de fiestas, véase Jenaro Alenda y Mira, Relaciones de solemnidades y fiestas públicas de España. Madrid, 1903.

${ }^{2 \pi}$ Soledad Carrasco, El moro de Granada en la literatura del siglo XV al $x X$, Revista de Occidente, 1956, p. 25.

${ }^{29}$ Soledad Carrasco, "Aspectos folclóricos y literarios de la fiesta de moros y cristianos en Españan, Publications of the Modern Language Association of America, 78 (1963), p. 483.

30 Ibidem, pp. 482-3. 
terizaba, pasó a convertirse en materia literaria, siendo uno de los motivos principales que integran el romancero de asunto morisco ${ }^{31}$.

El Condestable Miguel Lucas de Iranzo, además de jugar él mismo a las cañas con mucha frecuencia (Hechos, p. 36), instituye que sus caballeros practiquen este juego en Jaén todos los domingos y días de fiesta por dos motivos: para honrar y ennoblecer la ciudad de Jaén, y para que sus caballeros se adiestren en la lucha, obsequiando a los vencedores en ella con prendas moriscas (Hechos, pp. 116-7).

Los acontecimientos importantes y alegres en la vida de las personas - nacimientos, bodas - las grandes ocasiones - entrada de los reyes en las ciudades - y las festividades - Navidad, San Juan Bautista - se celebran con el juego de cañas. Este deporte se practicó en la boda del Condestable Lucas de Iranzo con doña Teresa de Torres (Hechos, pp. 47 y 58), en el nacimiento de sus hijos (pp. 258, 377 y 380), en la boda del tesorero Fernán Lucas con la hija del alcaide Pedro de Escavias (p. 438), y en la de Juan de Olid, secretario del Condestable, con la doncella Rendelez, criada de la condesa (p. 453).

El cronista de Alfonso XI narra en dos ocasiones cómo los sevillanos recibían a los reyes que iban a su ciudad: jugando a las cañas para manifestar su alegría. Asi lo hacen en la entrada en Sevilla de Alfonso XI de Castilla (GCA ${ }^{\circ} \mathrm{XI}, \mathrm{I}$, p. 399) y de Alfonso de Portugal y doña Maria de Castilla, a los que salieron a recibir caballeros, escuderos, ricos hombres «jugando todos a las cañas e todos aquellos juegos que entendian que era honrra e alegria... e Seuilla la muy honrrada con todos los de la frontera yvan muy honrrada mente jugando a las cañas e haziendo muy grandes alegrias" $\left(\mathrm{GCA}^{\circ} \mathrm{XI}, \mathrm{II}\right.$, p. 383). Cuando el rey Enrique IV visitó Jaén en 1458, el Condestable le obsequió con los deportes de correr toros y jugar cañas (Hechos, p. 18), como también a unos caballeros moros que fueron a visitarle y disfrutaron del espectáculo que ofrecían los caballeros de Jaén, "los quales salieron muy bien ajaezados, y ficieron un muy bravo juego de cañas, de que los moros estauan no poco espantados y marauillados, veyendo la feroçidad del juego y la desenboltura y moltitud de los caualleros de aquella çibdad» (Hechos, p. 110 ).

Para celebrar la Navidad de 1463, Miguel Lucas de Iranzo organizó en Jaén una serie de fiestas en las que predominaron las burlas moriscas, disfrazándose de moriscos la mitad de sus caballeros y llevando al Condestable una fingida carta del rey de Marruecos en la que le proponía que moros y cristianos jugasen a las cañas (Hechos, p. 99). El día de San Juan Bautista se celebraba también con juegos de cañas, según atestiguan los Hechos del Condestable (pp. 65 y 172) y la Crónica de los Reyes Católicos de Diego de

"Véase más ampliamente en Amelia García-Valdecasas, El género morisco en las fuentes del "Romancero general», UNED de Alzira-Valencia, Diputación de Valencia, 1987. 
Valera (p. 260). El día de San Juan era la cristianización del día celebrado por los musulmanes como la festividad del solsticio estival ( 24 de junio). Isabel de Alcázar celebraba este dia por medio de un baño ritual: "La mañana del dia de Sant Juan se vañaba e lavaba desnuda en una pila llena de agua»; esta morisca perpetuaba así «los ritos ancestrales de la fiesta de San Juan o Ansara de al-Andalus» $)^{32}$.

Nos han llegado noticias de esta visión del juego de cañas como manifestación de alegría y placer a través del relato de Adolf Hasenelever sobre la estancia del Dr. Johannes Lange en Granada en 1526:

La mencionada ciudad fue conquistada en el dia de San Juan por lo cual todos los años en dicho día los nobles y burgueses se van por la mañana temprano a las afueras de la ciudad armados a la morisca y con escudos y lanzas, después de comer, celebran escaramuzas y triunfos. El pueblo puede cazar y lidiar seis o siete toros y después vienen los nobles armados y montados a caballo, a la manera de los moros o de los turcos, divididos en dos grupos y luchan los unos con los otros hasta que un grupo huye para de nuevo volver a la pelea. Estos juegos los hemos visto en Granada en presencia del emperador y de la emperatriz acompañada de sus damas portuguesas en el día de San Juan y en ellos tres hombres fueron heridos de muerte por los toros y a un caballo le abrieron la cabeza con una caña y se quedó en tierraw" ${ }^{3 !}$.

Antonio Gallego Morel, al transcribir este texto sobre los juegos de cañas y fiestas de toros, ha puesto de relieve la confusión de Hasenelever en lo que se refiere a la fecha exacta de la conquista de Granada ${ }^{34}$.

El juego de cañas constituye, además, el cauce a través del cual las vestiduras moriscas usadas por los participantes en el juego pasan a otros usos.

\subsection{Vestiduras moras}

La adopción de prendas de vestir moras por los cristianos es uno de los aspectos de la maurofilia. Carmen Bernis ha tratado de establecer el origen

${ }^{32}$ Louis Cardaillac, Moriscos y cristianos. Un enfrentamiento polémico (1492-1640), Mexico, F.C.E., 1979, p. 42, ns. 93 y 94.

${ }^{33}$ Adolf Hasenelever, «Die tagebuchartigen Aufzeichnungen des pfälzischen Hofarztes Dr. Johannes Lange über seine Reise nach Granada im jahre 1526», Mitgeteilt und erlänter von... Archiv für Kulturgeschichte, Weimar, 5 (1907), pp. 420-23. Cfr. Antonio Gallego Morel, "La corte de Carlos V en la Alhambra en 1526», en Miscelánea de Estudios dedicados al profesor Antonio Marin Ocete, I, Granada, Univ. de Granada y Caja de Ahorros y Monte de Piedad, 1974, pp. 267-94.

${ }^{34}$ Ibidem, p. 275. 
y la naturaleza de la maurofilia en el vestir, y las preferencias castellanas en cuanto a vestiduras moras. El traje español "había acogido en el siglo XV algunas sugerencias del vestuario de los moros granadinos" ${ }^{35}$, porque en este siglo Castilla presencia el advenimiento de una época de riqueza y esplendor que se refleja en la adopción de lujosas vestiduras moras consideradas por los cristianos como el summun de riqueza y distinción. Los cristianos adoptaron la versión lujosa de las prendas de vestir moras, pues la riqueza y adornos eran lo que las relacionaba con el mundo árabe. Hacia mediados del siglo $X V$, el influjo morisco en el vestir y en las costumbres llegó incluso hasta Burgos, donde, sin embargo, no había moros desde el siglo $\mathrm{x}^{36}$. Tenemos el testimonio del barón de Rozmithal que, a propósito de un viaje por Castilla hacia la mitad del siglo XV, escribió que había visto "hermosas doncellas y señoras ricamente ataviadas a la usanza morisca, las cuales en toda su traza, y en sus comidas y bebidas, siguen dicha usanza. Unas y otras bailan danzas muy lindas al estilo morisco" ${ }^{37}$.

La nobleza y los reyes fueron los primeros que empezaron a utilizar el vestuario moro para las grandes ocasiones. El Condestable Lucas de Iranzo, con motivo de la alegría que le produjo el nacimiento de su hija, cabalgó "con una aljuba morisca de seda de muchos colores" (Hechos, p. 258), y para celebrarlo aquella noche se organizó un juego de cañas en el que la mitad de los participantes iban vestidos de "caualleros moriscos, con baruas postizas, y tiznados" (p. 259). En el recibimiento que dispensó la ciudad de Jaén al rey Enrique IV "salieron fasta quinientos roçines ... tocados a la morisca", $y$ unos treinta hombres "vestidos y calçados como moras, con panderos $y$ sonajas, dando muy grandes albórdolas» (p. 195); y cuando el Condestable se dirigía a Alcalá la Real para encontrarse con el rey llevaba un "capirote morisco" (p. 192), y los adalides que le acompañaban también iban tocados con "capirotes moriscos" (p. 189).

Como Enrique IV no permitiera a Miguel Lucas que le besara la mano, éste «satisfizo su deseo la real ropa besando, al modo morisco" (p. 192). Para celebrar la Navidad de 1463, unos cien caballeros de Jaén se vistieron "en hábito morisco" para participar en un juego de cañas en el que se enfrentarían con otros cien caballeros cristianos (pp. 98-9). El día de San Juan Bautista, el Condestable cabalgó "vestido y tocado a la morisca» (p. 171), y para celebrar su casamiento acudió a misa con un «tocado todo morisco» y cabalgando en un «cauallo tuneçi ... con las espuelas moriscas» (p. 52). En otras ocasiones, como en el alarde que hicieron los caballeros de Jaén

${ }^{35}$ Carmen Bernis, «Modas moriscas en la sociedad cristiana española del siglo xv y principios del XVI", Boletin de la Real Academia de la Historia, 144 (1959), p. 200.

${ }_{36}$ Américo Castro, La realidad histórica de España, México, Porrúa, 1962; seguimos la 4," ed., renovada, 1971 , p. 238.

${ }^{37}$ Viajes por España..., trad. A. M. Fabiè, "Libros de antaño», VIII, madrid, 1879, p. 162. 
en otoño, también se usan vestiduras moriscas: el Condestable acudió llevando "un capirote morisco" y acompañado por dos pajes "muy moriscos", y también los criados del Condestable se presentaron «vestidos y tocados a la morisca» (p. 138).

Carmen Bernis aporta tres documentos que hacen referencia a la adopción de vestidos moros por los cristianos. La mención de prendas moras - algunas para los juegos de cañas - aparece ya en el inventario de los bienes de Alfonso $\mathrm{V}$ de Aragón, redactado en 1424; en un relato de un italiano, que narra cómo el príncipe don Juan, el Rey Católico y los nobles de su séquito acudieron con indumentaria morisca a unos juegos de cañas que tuvieron lugar en Burgos, en honor de la princesa Margarita de Austria, recién llegada a España; y en otro relato de viajes del flamenco Lorenzo Vital, que vino a España acompañado de Carlos $V$ en su primer viaje, se cuenta el uso del traje morisco por un grupo de muchachas de San Vicente de la Barquera. La moda morisca debió de producir una honda impresión en Carlos V, porque cuando llegó a Aquisgrán para su coronación, lo hizo acompañado de unos jóvenes españoles que llevaban tocados a la morisca. En otro relato de este primer viaje de Carlos $\mathrm{V}$ a España, el marqués de Villena aparece llevando una toca morisca ${ }^{38}$. Es hacia mediados del siglo XV cuando se empiezan a mencionar en los inventarios de los bienes de los cristianos las tocas moriscas, la marlota - utilizada por los participantes en el juego de cañas durante más de dos siglos-, el sayo morisco, y los capellares y albornoces, dos tipos de mantos moriscos ${ }^{39}$.

Las joyas moriscas también despertaron la admiración de los cristianos. El cronista de los Hechos del Condestable comenta que los moros de Armilla y Aruriena iban "tan ricos y jaezados de tantas joyas y alhajas, que es cosa maravillosa poderse decir" (p. 87), y que estimularon la ambición de los cristianos, los cuales, tras conquistar aquellos lugares, se apropiaron de las joyas como parte del botín; "pues las joyas de oro, y de plata, y de seda, y de lana, y lienzos, y otras muchas preseas de diuersas maneras y de muy grand valia que de los dichos lugares tomaron y sacaron, no es quien lo pudiese numerar ni comparar; tanto fue» (p. 88), y así el Condestable "entró en la çibdad de Jahén, leuando ... muchos despojos de joyas y preseas muy ricas» (p. 89). El engalanarse exóticamente en las festividades vistiendo prendas moras - documentado en las crónicas y relatos de viajes- se convierte en una tradición que se plasmará en los romances del siglo $\mathrm{XV}$, en la descripción del moro, incluso cuando se le representa como guerrero ${ }^{40}$.

La coexistencia de árabes y cristianos dará lugar a mutuas influencias. Una de las manifestaciones concretas del profundo influjo que ejercieron

${ }^{38}$ C. Bernis, «Modas moriscas", pp. 200-2, 204 y p. 202, n. 2.

${ }^{39}$ Ibidem, pp. $205-24$.

${ }^{4} \mathrm{U} . \mathrm{K}$ noke, Die spanische, p. 332. 
las costumbres europeas sobre las moras la tenemos en la decoración de las paredes de la Alhambra, a base de pinturas de nobles y guerreros, contrariamente a la prescripción islámica contra la representación de la figura humana $^{41}$. Según Sánchez Albornoz, la adopción de costumbres cristianas por los musulmanes originó, en los siglos XIII y XIV, la "castellanización del reino de Granada» y, como consecuencia, la adopción por los musulmanes de Granada y Marruecos de «ideas caballerescas sobre la honra, la tradición. la fama y el amor de cuño castellano ${ }^{42}$, registrada por Diego Catalán. Sería como el envés oculto de una hoja cuyo haz hemos tratado de ir iluminando a través de una serie de ejemplos bien ilustrativos de la adopción de costumbres moriscas por parte de los cristianos castellanos.

\section{MaUrofilia e ideal Caballeresco}

El siglo XIV, a partir de la muerte de Alfonso XI, y más todavía el siglo $\mathrm{XV}$, son épocas dominadas por la lucha incesante entre nobleza y monarquía por conseguir el poder político y están presididos, pese al triunfo final del gobierno autoritario de los Reyes Católicos, por un fuerte proceso de aristocratización ideológica de la sociedad española. Entre la guerra civil fratricida del XIV (1366-1369), que encumbraría no sólo a una nueva dinastía, sino a toda una capa de nobleza nueva, y la del XV (1475-1478), a la muerte de Enrique IV, se da un crecimiento ininterrumpido de una potente aristocracia que, a la larga, será la que encumbre a los Reyes Católicos ${ }^{43}$. Como reconoce Luis Suárez, la interpretación de este período histórico como ese proceso de aristocratización, "entraña riesgos, pero permite aclaraciones muy sustantivas, la más importante acaso la posibilidad de comprender la amplia difusión de la moral caballeresca” ${ }^{44}$.

Las crónicas de este tiempo son los mejores testigos de ese proceso ${ }^{45}$.

4l Soledad Carrasco, The Moorish Novel: El Abencerraje and Pérez de Hita, Boston, Twayne Publishers, p. 146.

${ }_{42}$ Claudio Sánchez Albornoz, España, un enigma histórico, Buenos Aires, Sudamericana, 1956, I, p. 303.

${ }^{43}$ Luis Suárez Fernández, Nobleza y monarquia, Universidad de Valladolid, 1975. Las implicaciones literarias de ese auge nobiliario han sido bien analizadas por Roger Boase, $E l$ resurgimiento de los trovadores. Madrid, Pegaso, 1981.

4 L. Suárez, Nobleza, p. 10.

4 La consecuencia literaria más importante de ese proceso quizás sea la aparición y primeros desarrollos de un género nuevo, el biográfico, hasta entonces reservado exclusivamente a la realeza (para el tema todavía resultan básicos los trabajos de J. L. Romero, «Sobre la biografia española del siglo XV y los ideales de vida», Cuadernos de historia de España, I-II (1944), pp. 115-138, y Carlos Claveria, "Notas sobre la caracterización de la personalidad en Generaciones y semblanzas», Anales de la Universidad de Murcia, X (1951-2), pp. 481-526). 
Pero también la novelistica va a testificarlo de manera patente. Como ha señalado Martín de Riquer: «la novela caballeresca refleja una auténtica realidad social». Puesto que los caballeros reales (el mismo Diego de Valera, sin más) estaban imbuidos de literatura, muchos de sus actos respondian a los estímulos de los de los héroes en sus lecturas ${ }^{46}$.

Hemos comenzado nuestro artículo diciendo que la guerra en la Baja Edad Media fue una guerra fundamentalmente de desgaste. Pero, como ha señalado un experto en la materia, Philippe Contamine, la concepción de la guerra se va transformando durante la Edad Media, de manera que en los siglos XIV y XV constituye todo un fenómeno ideológico, que parece inseparable de la misma sociedad medieval, y cuya huella domina las diferentes vertientes artísticas, desde los castillos hasta la literatura, reflejando casi monotemáticamente el tema de la lucha ${ }^{47}$.

Como ha demostrado Maurice Keen, las justas, los pasos, los votos, las empresas, las divisas y las fiestas, todas esas manifestaciones de estilización no tienen por qué ser considerados como signos de pérdida de contacto con unos supuestamente primitivos y originales ideales caballerescos, sino como consecuencias naturales del desarrollo de la ciencia heráldica y del saber caballeresco. Los aspectos decorativos y teatrales, que partían originalmente de la verdadera lucha de guerra, suponían cada vez menos una destreza militar y más un arte deportivo. Como dice Keen, «la teatralidad y la decoración (...) llenaron el espacio dejado por el distanciamiento entre el deporte caballeresco y la actividad militar ${ }^{48}$.

En nuestro repaso por la literatura histórica de los siglos XIV y XV, y por encima de las transformaciones obvias durante este lapso de tiempo, apenas hemos advertido, sin embargo, grandes cambios de actitudes ideológicas básicas, en lo que respecta a la maurofilia, entre la Gran Crónica de Alfonso XI, las crónicas del Canciller Ayala y la Crónica de los Reyes Católicos de Diego de Valera, ni tampoco entre cualquiera de éstas y crónicas particulares como los Hechos del Condestable.

En la Gran Crónica de Alfonso XI encontramos la maurofilia en lo que podríamos llamar su "estado épico", de admiración sincera por el valor del adversario, muy distinta de la estilización "romántica» que encontramos en el Romancero morisco. Remite, es cierto, la consideración admirativa hacia el moro durante el periodo de los primeros Trastámara, representado en la

46 Martín de Riquer, Vida caballeresca en la España del siglo XV. Real Academia Española, Madrid, 1965, esp. pp. 94-5. Ya en el Poema de Alfonso XI de Rodrigo Yáñez se habla de la motivación que supuso para el rey la lectura de hechos caballerescos, cuando "vió libros que fablavan / del noble Cid Ruy Diaz (...) E vinole a coraçón / de con moros contender" ( strs. 284-5), ejemplo citado por Mercedes Vaquero, "Contexto literario de las crónicas rimadas medievales», Dispositio, X (1985), pp. 45-63.

${ }_{47}$ Philippe Contamine, La guerra..., cit., passim.

${ }^{48}$ Maurice Keen, La caballeria, pp. 265-6 y 272-3. 
Crónica de don Pedro I, pero ello porque los asuntos internos del reino obligaban a mirar hacia dentro y quedó relegado a un segundo plano el secular proyecto expansionista. Con Alvar García renace la consideración maurofilica, con un especial énfasis en asociar la fe religiosa a la lucha bélica (apreciable en algunas arengas, en el relato de milagros, en la calificación de don Fernando como "caballero de Cristo"...), propio tal vez del converso que pretende afianzar su posición entre el numeroso y receloso grupo de funcionarios de la cancillería real.

Los Hechos del Condestable reflejan la impregnación de costumbres moriscas, que otros escritores más moralistas, empezando por Alfonso de Palencia, atacarían en la vida muelle de Enrique IV. Finalmente, con Valera encontraremos de nuevo recuperado, a tenor del nuevo periodo que le tocó vivir, el aliento bélico coherente con la admiración caballeresca por el enemigo, que presidía las empresas bélicas de los Reyes Católicos, y que continuará presente en la maurofilia de las obras del XVI, y en concreto del Romancero morisco. Pero no será en estas crónicas, sino en un texto que tiene grandes concomitancias con la Crónica de los Reyes Católicos, la Historia de los hechos de don Rodrigo Ponce de León, marqués de Cádiz, donde llegue al máximo la sublimación de la batalla por la fe. En esta crónica particular la historia será ya concebida como unión perfecta entre reyes y caballeros, encarnaciones del plan de Dios en España. La caballería de los mártires sugerida por Alvar García para Fernando de Antequera o por Díez de Games para don Pero Niño son sólo un tímido anuncio de las descaradas sugerencias de santidad para el marqués de Cádiz ${ }^{49}$. Y cuando se han alcanzado estos límites tan absolutos, es obvio que el prestigio del enemigo deja de tener cabida. Sólo muchos años después de la conquista de Granada, tras la sublevación de los moriscos de las Alpujarras en 1575, sofocada por don Juan de Austria, cobraría el prestigio de los moros un nuevo aliento.

Los ideales caballerescos de los que nos habla Huizinga como comunes a toda la Baja Edad Media europea están, en nuestro caso castellano, y por razones fundamentalmente históricas, especialmente manifiestos en las crónicas, precisamente por su pretensión de veracidad, tras la que no puede dejar de latir el influjo ideológico de otros textos, de toda una tradición literaria. La profusión de alabanzas y halagos a la bondad y honra del enemigo parece no chocar en la prosa histórica con la descripción continua de crueles muertes, traiciones, codicias, violencias... Y era esto así, porque la caballeria era la clave mediante la cual el cronista interpretaba los hechos históricos. Esa oposición irreconciliable es neutralizada por la exaltación del hecho de armas, de la lucha entre iguales. La caballería continuaba

49 Véanse las conclusiones de Madeleine Pardo, «Les rapports noblesse-monarchie dans les chroniques particulières castillanes du XV siècle», en Homage a Marcel Bataillon. Les cultures ibériques en devenir, 1979, pp. 155-170. 
siendo la actividad en que el hombre se expresa de manera excelsa. Como dice Gutierre Díez de Games, "benzer vatalla es el mayor bien y la mayor gloria desta vida...". La preocupación final del caballero será siempre la de alcanzar honra, gloria y fama ${ }^{50}$.

La lucha contra el musulmán permitía cumplir con ese deber y derecho. La exaltación del enemigo, el respeto y la consideración de su valor, redundaría en nueva fama para el caballero. Será, en definitiva, una parte más dentro de la bella pintura en que la sociedad del XIV y XV necesitaba verse reflejada para sublimar los aspectos más dudosamente apreciables de su existencia. Como resumirá Huizinga, dentro del desorden que era la guerra de correrías e incursiones y la deficiente diplomacia, la historiografia "se apoderó de la ficción del ideal caballeresco, para reducirlo todo por medio de ella a un hermoso cuadro de honor de príncipes y de virtud de caballeros, a un lindo juego de nobles reglas ${ }^{51}$. Así pudo crear la ilusión de un orden en el inconsciente de un colectivo que lo exigia para comprender las evoluciones de su propio comportamiento social.

so El Victorial, p. 201. Cfr. tb. p. 35: «La noble fama es cosa propia a los caualleros».

"Johan Huizinga, El otoño de la Edad Media [1929], Madrid, Alianza, 1978, p. 95. 